\title{
Desain Sistem Rumah Cerdas berbasis Topologi Mesh dan Protokol Wireless Sensor Network yang Efisien
}

\author{
Design of Smart Home System based on Mesh Topology and \\ Efficient Wireless Sensor Network Protocol
}

\author{
Trio Adiono, Rachmad Vidya Wicaksana Putra, Maulana Yusuf Fathany, Waskita Adijarto \\ Pusat Mikroelektronika, Institut Teknologi Bandung, Jl. Tamansari 126, Bandung, Indonesia \\ Email:tadiono@stei.itb.ac.id
}

\begin{abstract}
In this publication, we propose a smart home system based on two approaches. First approach is mesh topology architecture and second one is an efficient Wireless Sensor Network (WSN) protocol. This system has two environments, indoor and outdoor. Indoor environment uses WSN system, while outdoor environment uses internet-cloud system. This scheme is known as Internet-of-Things (IoT). Indoor and outdoor environments are connected to each other by using a bridge. WSN system is established from WSN components which are connected in mesh topology. Each component of WSN is designed to implement the proposed efficient protocol. For outdoor environment, the existing internet-cloud system is the main infrastructure. Thus, this smart home system can be monitored and controlled from smart phone, anytime and anywhere, as long as mobile data access is provided. For system evaluation, tests have been done to deliver the system profile.
\end{abstract}

Keywords: Internet-of-Things, smart home system, wireless sensor network, mesh topology

\begin{abstract}
Abstrak
Dalam publikasi ini, kami mengusulkan sistem rumah cerdas berdasarkan dua pendekatan. Pendekatan pertama adalah arsitektur bertopologi mesh dan yang kedua adalah protokol Wireless Sensor Network (WSN) yang efisien. Sistem ini memiliki dua lingkungan kerja, indoor dan outdoor. Lingkungan indoor menggunakan sistem WSN, sedangkan lingkungan luar menggunakan sistem internet-cloud. Skema ini dikenal sebagai Internet-of-Things (IoT). Lingkungan indoor dan outdoor terhubung satu sama lain dengan menggunakan suatu jembatan penghubung. Sistem WSN dibentuk dari komponen-komponen WSN yang menggunakan topologi mesh. Setiap komponen dari WSN dirancang untuk mengimplementasikan protokol data efisien yang diusulkan. Untuk lingkungan outdoor, sistem internet-cloud yang ada adalah infrastruktur utama. Dengan demikian, sistem rumah cerdas ini dapat dipantau dan dikendalikan dari ponsel cerdas, kapan saja dan di mana saja, selama akses mobile data tersedia. Untuk evaluasi sistem, beberapa tes telah dilakukan untuk mendapatkan profil sistem.
\end{abstract}

Kata kunci: Internet-of-Things, sistem rumah cerdas, wireless sensor network, topologi mesh

\section{Pendahuluan}

Sistem informasi berbasis internet merupakan studi mendasar dalam konsep Internet-of-Things (IoT). Berbagai skenario penelitian dalam topik ini telah dipublikasikan, mulai dari physical layer hingga application layer. Kondisi ini mendorong perkembangan pesat konsep IoT ke skema lanjut, yaitu Internet-of-Everything (IoE). Konsep IoE ini tidak hanya membahas mengenai cara sekedar menghubungkan sesuatu berdasarkan fungsinya, tetapi juga membangun sistem yang mendukung

Received: 23 November 2015; Revised: 16 Februari 2015; Accepted: 17 Maret 2016 ; Published online: 30 Mei 2016 (C)2015 INKOM 2015/15-NO429 aplikasi yang cerdas (misalnya pemantauan status user, log aktivitas user, rencana perawatan dokter, dll). Ini adalah skema yang lebih kompleks dari sekedar komunikasi dasar Machine-to-Machine (M2M). Isu tentang topik IoT umumnya berkisar pada konsumsi daya, fleksibilitas sistem, sistem cerdas, self-configurable, dan isu keamanan. Mengenai isu-isu tersebut, ada beberapa penelitian yang dilakukan untuk mencoba mencari solusinya. Sebagai contoh, sistem operasi (OS) yang ringan (light-weight) menjadi solusi dalam mempermudah pengembangan aplikasi-aplikasi dan implementasi sistem [1]. Keunggulan dari OS ini adalah tingkat kebutuhan daya lebih rendah dibandingkan OS yang kompleks dan mudah untuk dikonfigurasi. Oleh karena itu, masalah konsumsi daya dan rendahnya fleksibilitas sistem dapat diselesaikan 
secara parsial dengan teknik ini. Beberapa penelitian tentang integrasi light-weight OS dalam Wireless Sensor Network (WSN) telah banyak dipublikasikan. Sebagai contoh, Harri Pensas et al mengusulkan integrasi Epis dengan TinyOS 2.0 [2]. Pada tahun 2012, Chunlong Zhang et al mengajukan integrasi WSN dengan $\mu \mathrm{C} / \mathrm{OS}-\mathrm{II}$ [3]. Selain pendekatan berbasis light-weight OS, beberapa protokol data telah diusulkan untuk memecahkan masalah IoT terkait, yaitu konsumsi daya yang efisien, sistem konfigurasi yang mudah, dan sistem yang aman. Sebagai contoh, Yuanbo Xu et. al. mengusulkan WZ-LCP dengan otentikasi dan pembaharuan kunci sebagai solusi untuk masalah keamanan [4]. Solusi lain adalah topologi jaringan mesh, terutama untuk aplikasi rumah cerdas yang heterogen. Topologi jaringan mesh memiliki fleksibilitas yang lebih besar terhadap gangguan dan memungkinkan beragam jalur untuk mencapai tujuan [5]. Pada dasarnya, area kajian IoT tidak hanya terfokus pada WSN, tetapi koneksi ke internet-cloud merupakan hal yang perlu dikaji juga. Sebuah perangkat yang berfungsi sebagai jembatan antara lingkungan luar (internet-cloud) dengan lingkungan dalam (WSN) memiliki peran penting. Karena, jembatan ini memiliki tanggung jawab untuk mengkonversi protokol data dan menyimpan data-data penting. Sebagai contoh, publikasi [6] mengusulkan penggunaan mesin database MySQL untuk penyimpanan data. Dengan menggunakan sistem database yang ini, manajemen informasi akan mudah dilakukan. Selain itu, jika kita bisa memilih sistem database yang low-cost (open-source dan light-weight), maka akan menjadi pilihan yang lebih baik. Dalam publikasi ini, kami mencoba untuk melengkapi konsep desain rumah cerdas dengan mendesain platform yang efisien dan mudah dikonfigurasi untuk sistem rumah cerdas. Hal ini didasarkan pada optimalisasi protokol data dan arsitektur WSN. Efisiensi yang ada didasarkan pada optimalisasi protokol data WSN yang telah diajukan dalam penelitian kami sebelumnya [5]. Sementara itu, konfigurabilitas didasarkan pada desain arsitektur topologi mesh dan program perangkat lunak yang ditanamkan. Terkait dengan WSN, kita menggunakan tiga jenis koneksi, yaitu ZigBee, bluetooth, dan WiFi. Setiap jenis koneksi bisa menjadi pelengkap satu sama lain, sehingga kelemahan dari masing-masing koneksi dapat dihilangkan. Untuk sistem databasing, kami menggunakan sistem SQLite karena low-cost dan ringan untuk diimplementasikan. Dalam sistem databasing ini, kita menyimpan setiap informasi penting tentang status perangkat yang terhubung.
Publikasi ini disusun dalam beberapa bagian. Bagian pertama adalah pengenalan tentang latar belakang penelitian dan beberapa penelitian yang terkait. Bagian kedua adalah tentang arsitektur sistem yang diusulkan. Bagian ketiga adalah tentang evaluasi eksperimen dan analisis yang terkait. Lalu, diikuti oleh kesimpulan dan rencana riset lanjut. Bagian terakhir dari publikasi ini adalah referensi.

\section{Desain arsitektur sistem}

Dalam konsep rumah cerdas yang diusulkan, lingkungan sistem dibagi menjadi dua (outdoor dan indoor), yaitu sistem berbasis internet-cloud dan Wireless Sensor Network (WSN). Kedua lingkungan tersebut saling terhubung satu sama lain dengan menggunakan jembatan access point, sehingga koneksi indoor-outdoor ini dapat dipandang sebagai konsep Internet-of-Things (IoT). Pada dasarnya, visi kami untuk konsep rumah cerdas tidak hanya menghubungkan perangkat ke internet tetapi juga membangun lingkungan cerdas. Lingkungan indoor akan dibentuk dari sistem Wireless Sensor Network (WSN) berdasarkan protokol tertentu yang akan dibahas kemudian. Sementara itu, lingkungan luar akan menggunakan skema internet-cloud yang ada.

\subsection{Lingkungan kerja}

Lingkungan indoor memiliki empat bagian utama berdasarkan fungsinya: access point, WSN host, WSN nodes, dan WSN end-points. Access Point (AP) bertanggung jawab untuk menghubungkan sistem internet di outdoor dengan sistem WSN indoor. Oleh karena itu, AP akan mendistribusikan alamat Internet Protocol (IP) untuk perangkat yang seharusnya terhubung ke internet (misalnya smartphone, WSN host). WSN host bertanggung jawab untuk menjadi koordinator WSN. Ini adalah pusat kendali WSN. Sehingga dia harus bisa memahami semua protokol yang terhubung. Selain itu, WSN host harus tahu semua info (nomor identifikasi, status, konfigurasi, dll) dari semua perangkat yang terhubung (WSN nodes dan WSN end-devices). Sebaliknya, WSN nodes memiliki tanggung jawab yang paling sederhana dalam sistem WSN. Dia hanya perlu meneruskan setiap data yang diterima tanpa repot-repot tahu di mana alamat tujuan akhir. Dengan skenario ini, kita dapat menambahkan node sebanyak yang kita butuhkan tanpa khawatir tentang pengalamatan. Untuk perangkat WSN endpoint, desain ini terkait dengan aplikasi. Mereka harus dipantau dan diperbarui secara berkala ke dalam sistem database pada WSN host. Karena, dari database ini, user dapat mengakses semua informasi dan memantau status dari semua 
perangkat. Dalam sistem WSN, kita menggunakan tiga protokol komunikasi, yaitu ZigBee, bluetooth, dan IEEE 802.11b (WiFi). Masing-masing protokol tersebut memiliki kelebihan dan kekurangan. Menggabungkan ketiganya bersama ke dalam satu sistem dapat menghilangkan kelemahan yang ada. Perbandingan dari ketiga protokol dapat dilihat pada Tabel 1. ZigBee memiliki poin positif pada kesederhanaan struktur data dan jangkauan, tetapi lemah pada data-rate. Oleh karena itu, ZigBee cocok sebagai back-bone koneksi perangkat nodes dan end-point yang hanya memerlukan tingkat data dan konsumsi daya yang rendah, namun digunakan secara terus-menerus. Sementara itu, koneksi bluetooth memiliki poin yang kuat pada data-rate dan kompatibilitas untuk terhubung ke smart-phone. Oleh karena itu, bluetooth cocok digunakan untuk aplikasi smart-phone yang membutuhkan data-rate rendah atau menengah. Terakhir, WiFi memiliki poin yang kuat pada tingkat komunikasi dengan data-rate yang tinggi dan kompatibilitas untuk terhubung ke smartphone. Oleh karena itu, WiFi cocok untuk penggunaan aplikasi smart-phone yang perlu data rate tinggi (misalnya video streaming). Koneksi WiFi juga dapat membangun komunikasi antara WSN dengan internet-cloud. Oleh karena itu, sistem WSN bisa mendapatkan alamat IP yang akan dikelola oleh access point bridge untuk tujuan pengendalian luar ruangan (outdoor).

Tabel 1. Perbandingan ZigBee, Bluetooth dan WiFi [7]

\begin{tabular}{llll}
\hline \multicolumn{1}{c}{ Fitur } & ZigBee & Bluetooth & $\begin{array}{l}\text { IEEE } \\
802.11 \mathrm{~B}\end{array}$ \\
\hline Kompleksi- & Simpel & Kompleks & $\begin{array}{l}\text { Sangat } \\
\text { Kompleks } \\
\text { tas }\end{array}$ \\
Jangkauan & $300 \mathrm{~m}$ & $10 \mathrm{~m}$ & $100 \mathrm{~m}$ \\
Data rate & $250 \mathrm{Kbps}$ & $1 \mathrm{Mbps}$ & $11 \mathrm{Mbps}$ \\
\hline
\end{tabular}

Untuk koneksi arsitektur utama dalam WSN, kita memilih topologi mesh, karena memiliki keunggulan dalam scalability. Jika kita ingin memperluas WSN, kita hanya perlu menambahkan nodes atau perangkat end-points di area yang terjangkau nodes atau end-points lainnya. Selain itu, topologi mesh memiliki performa dan kehandalan yang terbaik dibandingkan topologi star atau tree [8]. Kelebihan penggunaan teknologi topologi mesh di dalam sistem WSN ini adalah: (1) fleksibilitas yang tinggi, karena dengan hanya menambahkan node, maka dia akan menemukan node atau point yang terdekat dan membentuk rute yang sesuai; (2) sistem menjadi robust, karena jika salah satu node atau point tidak bisa digunakan, maka rute alternatif akan langsung dibentuk; (3) peluasan area jangkauan bisa dilakukan dengan menggunakan devais yang diletakkan di antara jalur yang sudah ada; (4) setiap node atau point akan berkomunikasi dengan node atau point yang dekat saja, sehingga meminimalkan interferensi komunikasi; (5) kehadiran jalur alternatif akan menambah alternatif utilitas devais, berbeda dngan topologi tree yang akan mengalami kemacetan jika jumlah sub-nodes bertambah [9]. Lingkungan outdoor dirancang untuk tujuan mobilitas, sehingga user bisa memonitor setiap perangkat di rumah yang terhubung ke sistem WSN, kapan saja dan di mana saja. Oleh karena itu, pengguna smart-phone atau gadget perlu terhubung ke internet-cloud. Access point bridge akan mengelola setiap perangkat pada sistem WSN yang seharusnya terhubung ke internet-cloud, dengan alamat IP tertentu. Dengan skema ini, user dapat memantau dan mengontrol perangkat apapun di dalam sistem rumah cerdas yang terhubung dengan sistem, kapan saja dan di mana saja. Ilustrasi arsitektur yang diusulkan lengkap disajikan pada Gambar 1.

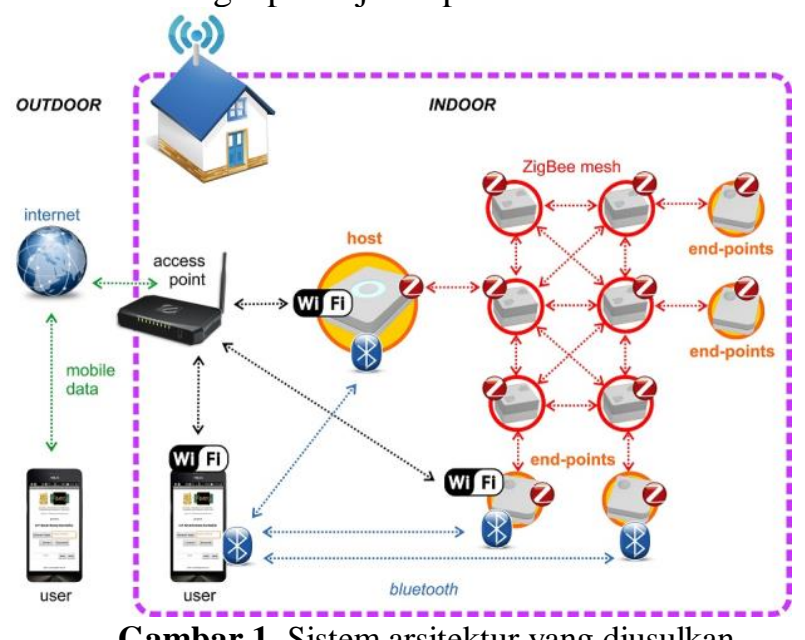

Gambar 1. Sistem arsitektur yang diusulkan

\subsection{Protokol data yang efisien}

Dalam sistem WSN ini, kami menggunakan desain protokol data seperti yang ditunjukkan pada Tabel 2 , seperti yang telah diusulkan dalam penelitian kami sebelumnya, pada paper [5]. Dengan protokol data ini, kita dapat merancang sebuah paket data yang efisien untuk setiap aplikasi. Informasi data yang tersedia seperti jenis informasi, kontinuitas data, hingga panjang data payload tercakup di dalamnya. Metode pengemasan informasi ini berdampak pada konsumsi daya. Besar efisiensi penggunaan daya bergantung pada pemanfaatan karakter informasi yang dapat direpresentasikan dengan 1-byte packet-init.

Tabel 2. Desain protokol data

\begin{tabular}{lllll}
\hline Header & Adress & $\begin{array}{l}\text { Paket } \\
\text { Init }\end{array}$ & $\begin{array}{l}\text { Data } \\
\text { Payload }\end{array}$ & Cheksum \\
\hline 3-byte & 2-byte & 1-byte & n-byte & 1-byte \\
\hline
\end{tabular}




\subsection{Sistem databasing}

Sistem databasing dirancang dengan menggunakan sistem SQLite. SQLite dipilih karena low-cost dan mudah untuk diimplementasikan ke dalam sistem rumah cerdas. Untuk bisa mengimplementasikan data ke SQLite, kita perlu mendefinisikan alamat perangkat dalam register SQLite. Pengalamatan register mengambil referensi dari kerja riset kami sebelumnya [5] untuk diterapkan dalam penelitian ini. Pengalamatan register perangkat disajikan pada Tabel 3 dan diimplementasikan dalam sistem SQLite dengan menggunakan pemrograman Python. Contoh penerapan sistem database SQLite ditunjukkan pada Gambar 2. Penerapan pada sistem SQLite menggunakan beberapa informasi, yaitu nomor utama, nomor identifikasi perangkat yang sebenarnya, status perangkat, dan tanggal pengolahan, dan waktu pemrosesan. Dengan menggunakan format ini, kita hanya perlu untuk mendefinisikan nama perangkat, identifikasi, dan definisi status.

Tabel 3. Register pengalamatan perangkat

\begin{tabular}{clcc}
\hline Kategori & End-Points & Alamat & n-Byte \\
& Temperatur & 0x01 & 2 \\
Monitor & Kelembaban & 0x02 & 2 \\
& Lain-lain & $\ldots$ - 0x3F & $\ldots$ \\
\hline \multirow{5}{*}{ Kontrol } & Lampu & 0x30 & 1 \\
& Switch & 0x31 & 1 \\
& Gorden & 0x32 & 2 \\
& IrDA & 0x33 & 78 \\
& VLC & 0x34 & 32 \\
& Lain-lain & $\ldots-0 \times B F$ & $\ldots$ \\
\hline \multirow{3}{*}{ Kombinasi } & Keypad & 0xC0 & 2 \\
& Kunci & 0xC1 & 1 \\
& Lain-lain & $\ldots$ - 0xFF & $\ldots$ \\
\hline
\end{tabular}

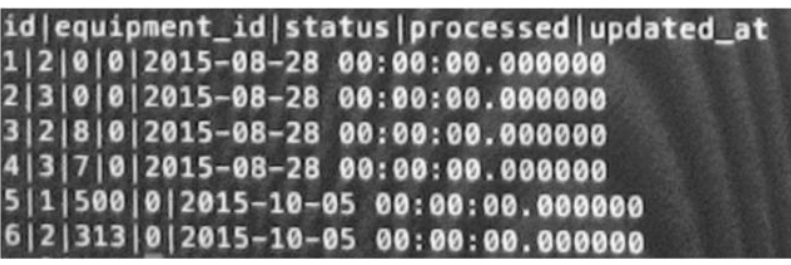

Gambar 2. Contoh format struktur database SQLite

\section{Evaluasi dan analisis}

Dalam rangka melakukan evaluasi eksperimental, kita perlu mendefinisikan lokasi tes. Gambar 3 mengilustrasikan posisi host dan delapan lokasi tes di ruangan laboratorium kami (Laboratorium IC Design, ITB). Lokasi-1 terletak di ruangan yang sama dengan WSN host dan hanya dipisahkan dengan dua bilik kecil. Lokasi-2 dan lokasi-3 terletak di ruangan yang berbeda dengan WSN host dan hanya dipisahkan oleh dinding dan pintu.
Lokasi-4, lokasi-5, lokasi-6, dan lokasi-7 terletak di berbagai ruangan berbeda dengan tempat sebelumnya, di mana mereka dipisahkan oleh satu ruangan besar dari WSN host. Terakhir, lokasi-8 terletak di sebuah ruangan yang dipisahkan oleh dua kamar besar dari WSN host. Untuk evaluasi ini, kita menggunakan XBee 900HP (ZigBee) sebagai perangkat komunikasi pengirim dan penerima. Receiver ini ditempatkan di lokasi-1 hingga lokasi-8 sesuai ilustrasi. Sebagai pemancar data atau WSN host, kami menggunakan Raspberry $P i$ yang dikonfigurasi bersama dengan XBee 900HP (ZigBee).

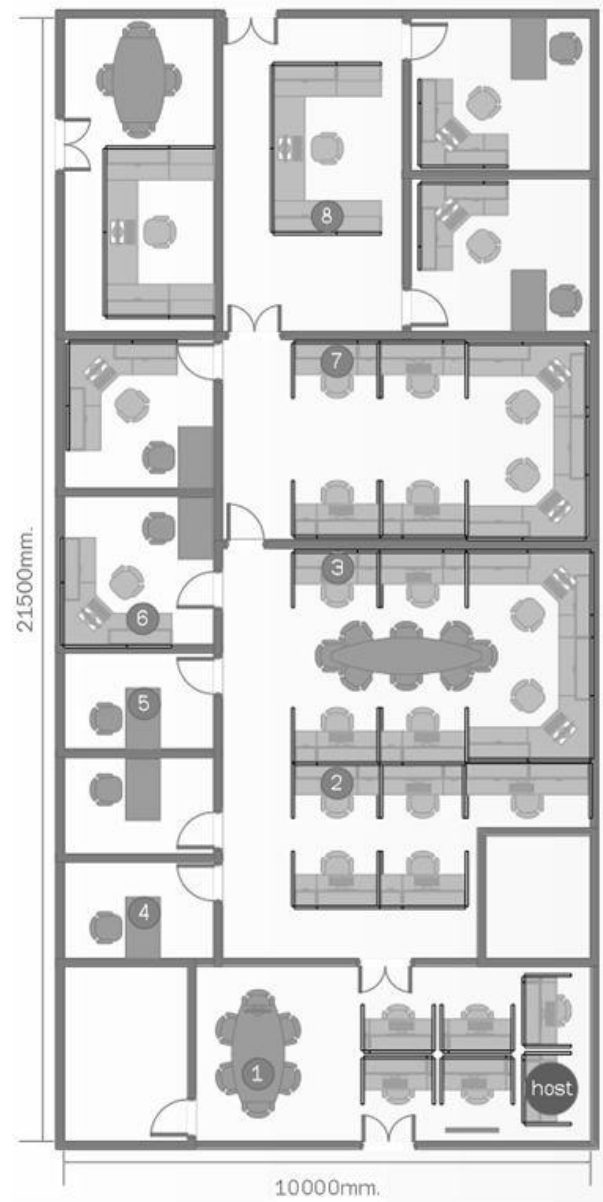

Gambar 3. Skenario lokasi tes eksperimen

\subsection{Analisis RSSI pada sinyal WSN}

Eksperimen pertama adalah mengenai pengukuran Received Signal Strength Indicator (RSSI) yang dilakukan untuk protokol WSN (ZigBee) dengan berbagai tingkat kekuatan transmisi dan lokasi. Tujuan dari evaluasi RSSI ini adalah untuk melihat kekuatan sinyal WSN untuk menghadapi berbagai macam tantangan posisi, hambatan, dan gangguan pada medium transmisi. Gambar 4 - Gambar 8 menyajikan data hasil pengukuran RSSI untuk beberapa daya transmisi yang berbeda. Daya terendah (lowest) adalah $5 \mathrm{~mW}(+7 \mathrm{dBm})$, daya rendah (low) adalah $32 \mathrm{~mW}(+15 \mathrm{dBm})$, daya menengah (medium) adalah $63 \mathrm{~mW}(+18 \mathrm{dBm})$, 
daya tinggi (high) adalah $125 \mathrm{~mW}(+21 \mathrm{dBm})$, dan daya terkuat (highest) adalah $250 \mathrm{~mW}(+24 \mathrm{dBm})$.

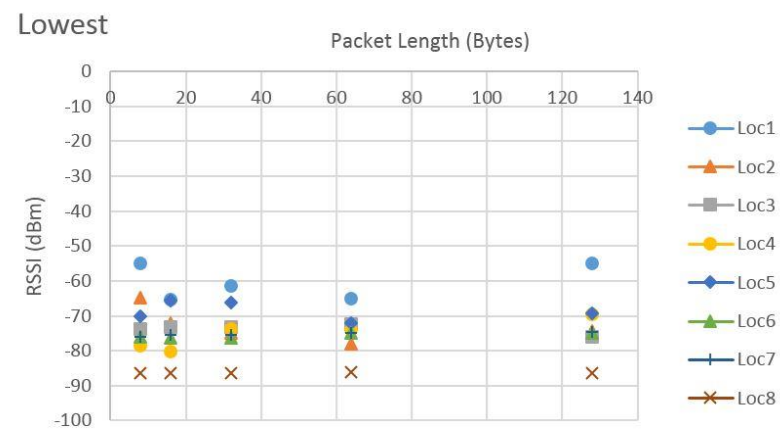

Gambar 4. Data RSSI pada daya transmisi terendah

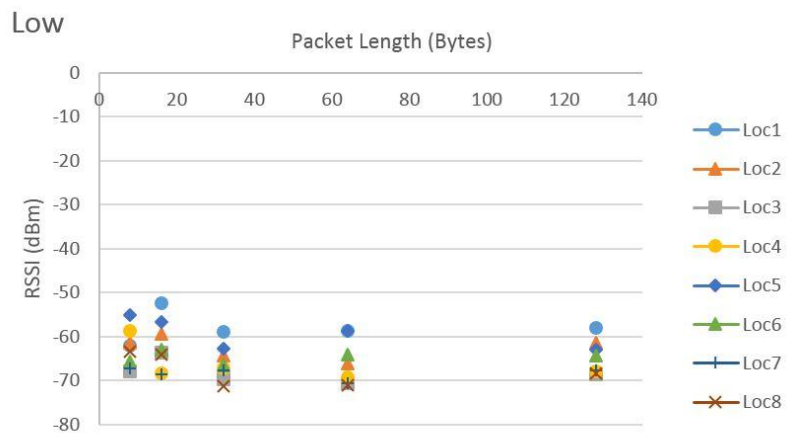

Gambar 5. Data RSSI pada daya transmisi rendah

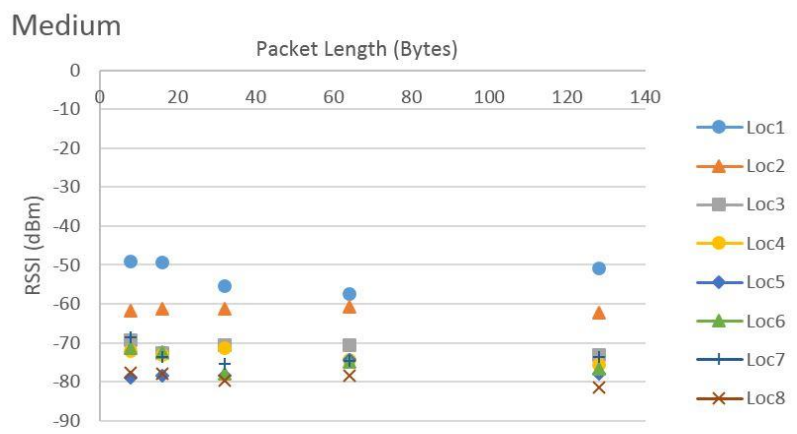

Gambar 6. Data RSSI pada daya transmisi menengah

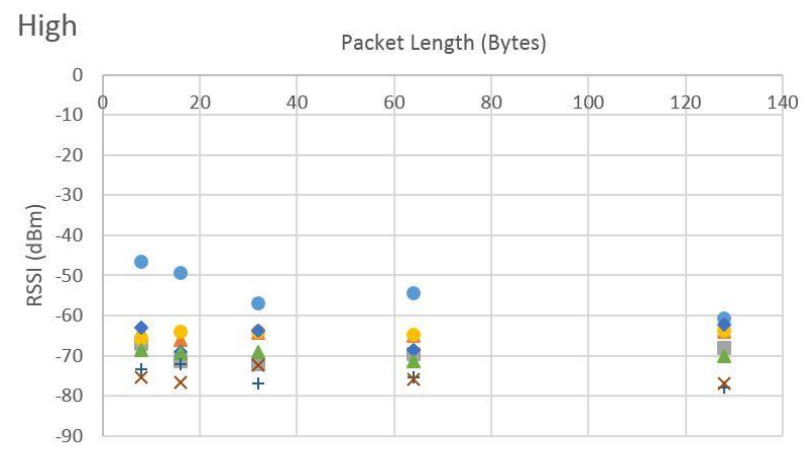

Gambar 7. Data RSSI pada daya transmisi tinggi

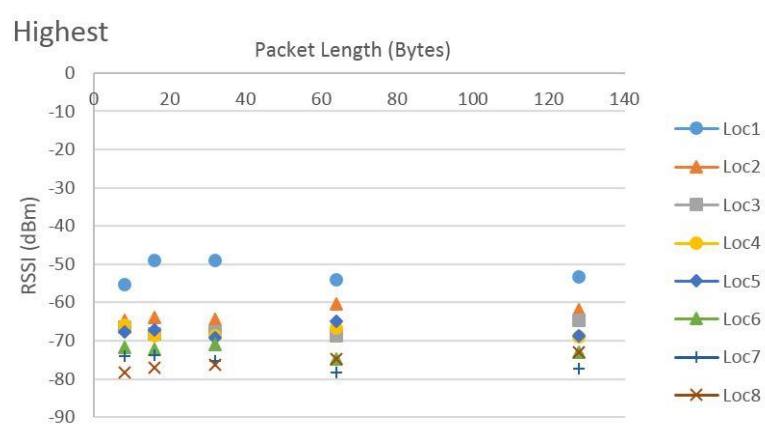

Gambar 8. Data RSSI pada daya terkuat

Jika kita amati grafik ini, kita akan menemukan bahwa dari lokasi terdekat (lokasi-1) dan terjauh (lokasi-8), menerima data dengan RSSI yang berbeda (penurunan) sekitar $30 \mathrm{dBm}$. Data sinyal RSSI yang terukur menunjukkan bahwa jarak dan hambatan pada medium transmisi data akan mempengaruhi kekuatan sinyal. Penurunan yang signifikan tentu ditemukan ketika ada penghalang (obstacles). Misalnya, RSSI data pada lokasi-1 dan lokasi-2 secara signifikan menurun. Oleh karena itu, jika kita ingin mengoptimalkan jarak sinyal ZigBee, kita perlu mempertimbangkan struktur dan bahan penghalang. Lebih jauh lagi, nantinya kita juga perlu mempertimbangkan adanya interferensi dari sinyal lain yang bertabrakan.

\subsection{Data throughput pada lingkungan WSN}

Data throughput adalah jumlah data yang dapat diterima dan diproses dengan sempurna oleh penerima. Tujuan dari evaluasi data throughput ini adalah untuk melihat kemampuan kecepatan penerimaan data pada node dan end-devices yang berada dalam sistem WSN. Untuk evaluasi ini, kita menggunakan mikroprosesor STM32L1 dan XBee 900HP (ZigBee) sebagai titik akhir perangkat penerima. Receiver ini ditempatkan di lokasi-1. Sebagai pemancar, kami menggunakan Raspberry $P i$ yang dikonfigurasi dengan XBee 900HP (ZigBee) sebagai WSN host. Pemancar ini ditempatkan di lokasi host. Oleh karena itu, penerima dan pemancar dipisahkan sejauh $5 \mathrm{~m}$. Transmitter diprogram untuk mengirim karakter terus menerus, sementara penerima diprogram untuk menerima dan menghitung data yang diterima. Untuk setiap detik, mikroprosesor STM32L1 akan mengirimkan hasil penghitungan pada LCD untuk tujuan display. Hasil tes data throughput yang ini disajikan pada Gambar 9 sebagai grafik tunggal. Pada grafik tersebut, kita bisa melihat bahwa jumlah baudrate akan mempengaruhi kinerja hasil throughput. Hal ini logis diterima, karena dengan kinerja baudrate yang lebih tinggi, sampling data yang diterima akan lebih tinggi juga. Nilai tertinggi dari uji throughput 
bisa mencapai hampir 45000 bit/detik. Selain itu, terlihat bahwa dengan pilihan baudrate 115200 , hasil data throughput tidak signifikan terhadap pilihan baudrate 57600. Artinya, untuk pilihan aplikasi low power, baudrate 57600 bisa menjadi pilihan yang optimal.

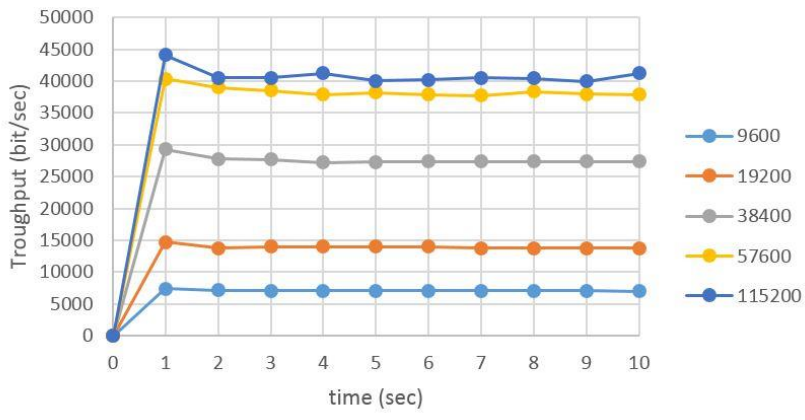

Gambar 9. Grafik throughput berdasarkan baudrate

\subsection{Komunikasi bluetooth}

Uji komunikasi bluetooth dilakukan dengan cara mengirimkan data dari smart-phone ke WSN host melalui bluetooth. Tujuan dari evaluasi ini adalah untuk melihat fungsionalitas komunikasi smartphone dengan sistem WSN. Gambar $10-$ Gambar 11 menunjukkan bahwa ketika kita mengirim empat karakter dari smart-phone, maka WSN host akan menerima setiap karakter tunggal (per-byte) secara independen dalam waktu yang berbeda, sehingga menyimpannya satu-per-satu.

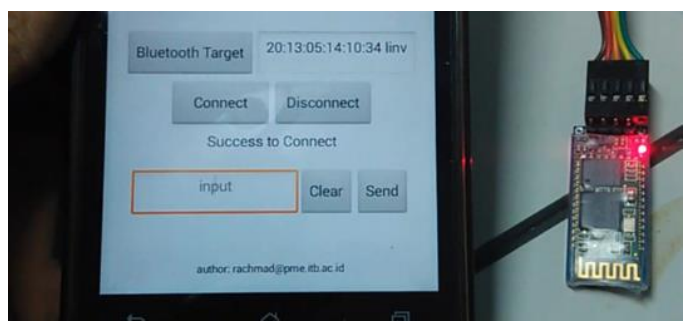

Gambar 10. Tes konektivitas pairing smart-phone

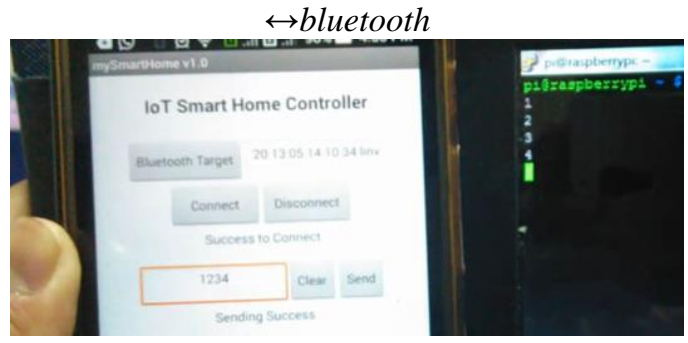

Gambar 11. Tes pengiriman data smart-phone $\leftrightarrow$ bluetooth $\leftrightarrow$ WSN host

Hasil evaluasi ini menunjukkan bahwa program rumah cerdas kami pada smart-phone bisa bekerja dengan baik dan membangun koneksi bluetooth dengan modul bluetooth di WSN host. Ini adalah tes penting untuk memastikan bahwa user dapat mengirim perintah melalui nirkabel dari ponsel pintar ke WSN host. Selain itu, eksperimen ini menunjukkan bahwa format protokol yang dibuat telah berhasil diimplementasikan dengan baik.

\subsection{Tes kombinasi komunikasi pada WSN}

Untuk melakukan tes kombinasi komunikasi ini, kami menggunakan fungsi saklar dan relay. Kami merancang tes dengan menggunakan lampu LED dan monitor LCD sebagai perangkat WSN endpoints. Kami mengendalikan mereka menggunakan sebuah aplikasi pada smart-phone. Aplikasi smartphone ini terhubung ke WSN host melalui protokol dan jalur komunikasi bluetooth. Ketika perintah dipilih, smart-phone akan mengirim mereka ke WSN host melalui bluetooth. Kemudian, data yang diterima di WSN host diproses dan dikirim ke WSN end-points dengan menggunakan protokol dan jalur komunikasi ZigBee.

Dalam skenario ini, ada konversi protokol data yang diolah oleh WSN host. Selanjutnya, data yang dikirimkan dari WSN host melalui ZigBee akan diterima oleh perangkat end-points dan diterjemahkan menjadi representasi perintah fisik. Lampu LED merespon dengan menyala berwarna merah, sedangkan monitor LCD merespon dengan menyala dan menampilkan display seperti yang ditunjukkan pada proses tes Gambar 12 - Gambar 14. Eksperimen ini menunjukkan bahwa sistem dan protokol data yang diusulkan dapat bekerja dengan baik.

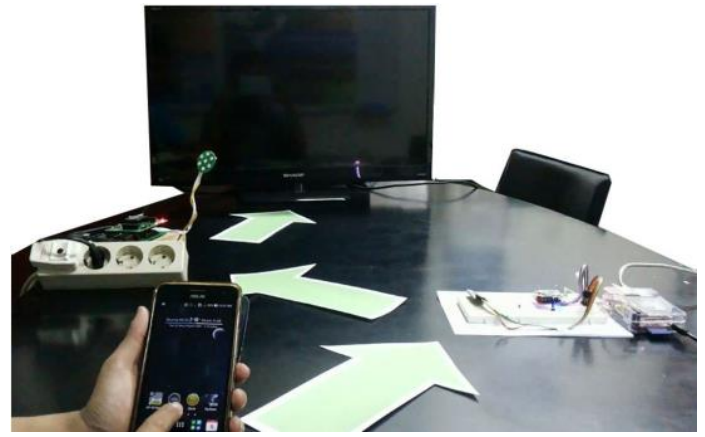

Gambar 12. Tes kombinasi - pemanggilan mobile app

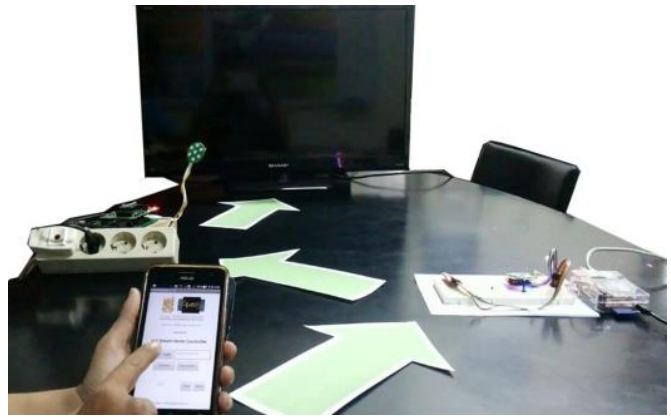

Gambar 13. Tes kombinasi - pemilihan perintah mobile app 


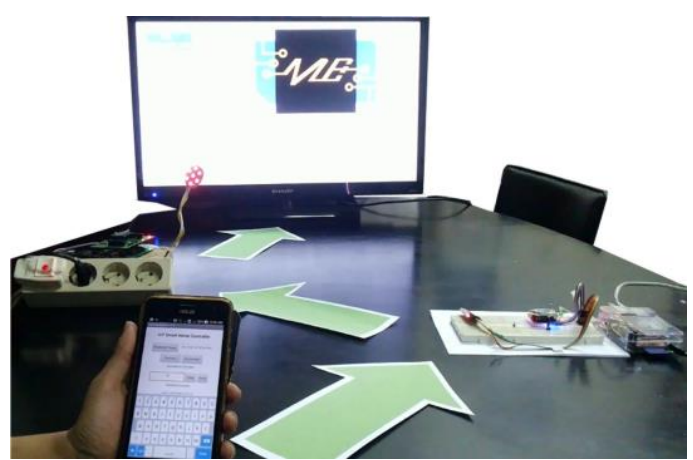

Gambar 14. Tes kombinasi -end-points menyala

\section{Kesimpulan dan future outlook}

Dalam penelitian ini, kami mengusulkan desain sistem rumah cerdas yang berbasis protokol data WSN yang efisien dan arsitektur sistem indoor bertopologi mesh. Dalam konsep rumah cerdas ini, lingkungan sistem dibagi menjadi dua lingkungan utama, indoor dan outdoor. Lingkungan outdoor menggunakan sistem berbasis internet-cloud, sementara lingkungan dalam menggunakan sistem WSN. Kedua lingkungan saling terhubung satu sama lain dengan menggunakan jembatan access point. Komponen WSN saling terhubung satu sama lain pada topologi mesh untuk memberikan arsitektur scalable. Untuk pelaksanaan databasing, sistem database SQLite dipilih karena low-cost dan mudah dikonfigurasi. Untuk evaluasi sistem, protokol dan arsitektur yang diusulkan dapat bekerja dengan baik dan bisa digunakan untuk implementasi lebih lanjut.

Untuk penelitian masa depan, kami akan menambah perilaku cerdas dalam sistem. Konsep smart learning diharapkan akan membuat sistem rumah cerdas dapat memahami kebiasaan dan kebutuhan user. Hal ini akan membuat sistem rumah cerdas mampu meningkatkan kualitas dan produktivitas user.

\section{Ucapan Terimakasih}

Penelitian ini didukung oleh program Penelitian Unggulan Perguruan Tinggi, Desentralisasi DIKTI, 2015.

\section{Daftar Pustaka}

[1] T. Adiono, Challenges and opportunities in designing internet of things, "Proc. of Int. Conf. on Information Technology, Computer and Electrical Engineering", November 2014, pp.11-12.

[2] H. Pensas, H. Raula, and J. Vanhala, Energy efficient sensor network with service discovery for smart home environments, "Proc. of Int. Conf. on Sensor Technologies and Application", June 2009, pp.399-404,.
[3] C. Zhang, M. Zhang, Y. Su, and W. Wang, Smart home design based on ZigBee wireless sensor network, "Proc. of Int. ICST Conference on Communications and Networking in China", August 2012, pp.463-466.

[4] Y. Xu, Y. Jiang, C. Hu, H. Chen, L. He, and Y. Cao, A balanced security protocol of wireless sensor network for smart home, "Proc. of Int. Conf. on Signal Processing", October 2014, pp.23242327.

[5] M.Y. Fathany and T. Adiono, Wireless protocol design for smart home on mesh wireless sensor network, "Int. Symp. on Intelligent Signal Processing and Communication System", Bali, November 2015.

[6] S. Sankaranarayanan and A.T. Wan, ABASH android based smart home monitoring using wireless sensors, "Proc. of IEEE Conf. on Clean Energy and Technology", November 2013, pp.494499.

[7] V. Abinayaa and A. Jayan, Case study on comparison of wireless technologies in industrial applications, "Int. J. of Scientific and Research Publications", Vol. 4, Issue 2, February 2014.

[8] Z. Bi, Smart home with ZigBee: hardware simulation and performance evaluation, "Proc. of Int. Conf. on Mechatronic Sciences, Electric Engineering and Computer", pp.2139-2142, December 2013.

[9] H.-L. Shang, R.-M. Xu, and J.-K. Yuan, Smart home system based on ZigBee and IOS software, "Proc. of Int. Conf. on Parallel and Distributed Systems", pp.940-944, December 2012. 
72 • INKOM, Vol. 9, No. 2, November 2015: 65-72 